PUSTABIBLIA: Journal of Library and Information Science

ISSN 2549-3493 (Print); ISSN 2549-3868 (Online)

DOI: http://dx.doi.org/10.18326/pustabiblia.v3i2.223-237

SK Dirjen Risbang-Kemristekdikti No 23/E/KPT/2019 (Peringkat 4 SINTA)

\title{
Promosi Perpustakaan Melalui Media Sosial di Perpustakaan IAIN Salatiga
}

\author{
Ifonilla Yenianti \\ Pustakawan IAIN Salatiga \\ Ifon_2006@yahoo.com
}

\begin{abstract}
One of the five laws of the library is that a library is a growing organism. Library is not an institution in the "static" or "silent" condition, but the library will be follow and adjust the development of the times dynamically. The development of the library that is currently in the 21st century is definitely different from the development of the library in the 19th century, not only in terms of the development of this writing takes the theme of library promotion by looking directly at the role of the Salatiga IAIN library in carrying out various promotional activities. This writing of this article using the ethnographic approach in order to describe the culture of the library in terms of promotion. The conclusion of this article is promotion as one of the activities of library marketing (library marketing) and be come the key of the continued use of the library by its users. Likewise the existence of social media is not a competitor but rather a means for promotion that makes it easy for librarians to communicate with users. The Salatiga IAIN Library uses social media in the form of websites and youtube accounts as promotional media to communicate its services, activities and wealth of reference resources to users.
\end{abstract}

\begin{abstract}
Abstrak
Salah satu hukum dasar perpustakaan dari S.R. Ranganathan adalah Library is Growing Organism (Barner, 2011) bahwa perpustakaan bukanlah suatu lembaga yang "statis" atau "diam" namun akan selalu dinamis mengikuti dan menyesuaikan perkembangan zaman. Perkembangan perpustakaan yang sekarang ini di abad 21
\end{abstract}


pasti berbeda dengan perkembangan perpustakaan di abad 19, tidak hanya dari sisi perkembangan penulisan ini mengambil tema tentang promosi perpustakaan dengan melihat secara langsug peran perpustakaan IAIN Salatiga dalam melakukan berbagai kegiatan promosi. Penulisan menggunakan pendekatan etnografi dalam rangka mendeskripsikan budaya perpustakaan dalam hal promosi. Kesimpulan dari penulisan ini adalah bahwa Promosi sebagai salah satu kegiatan library marketing (pemasaran perpustakaan) menjadi kunci dari keberlangsungan keterpakaian perpustakaan oleh para penggunanya. Begitu juga keberadaan media sosial bukan menjadi pesaing melainkan menjadi sarana untuk promosi yang memudahkan para pustakawan untuk berkomunikasi dengan para pengguna. Perpustakaan IAIN Salatiga menggunakan media sosial berupa website dan akun Youtube sebagai media promosi untuk mengkomunikasi layanan-layanan, kegiatan-kegiatan, dan kekayaan sumber referensi yang dimilikinya kepada para pengguna.

Keywords: library, librarian, promotion, social media.

\section{Pendahuluan}

Undang-undang nomor 43 tahun 2007 tentang perpustakaan mendefinisikan perpustakaan khusus sebagai "perpustakaan yang diperuntukkan secara terbatas bagi pemustaka di lingkungan lembaga pemerintah, lembaga masyarakat, lembaga pendidikan keagamaan, rumah ibadah dan organisasi lain”. Sedangkan Sulistyo-Basuki (1994) menggambarkan perpustakaan khusus sebagai sebuah perpustakaan yang dapat dilihat dari empat unsur yang tidak dapat dipisahkan yakni status atau kedudukan perpustakaan, pengelola perpustakaan, koleksi perpustakaan, dan pemakai perpustakaan.

Perpustakaan IAIN Salatiga dapat dikatergorikan perpustakaan khusus dimana sebagian besar koleksinya adalah buku-buku atau literatur tentang Agama Islam dan koleksi umum sebagai koleksi penunjang. Tupoksi dari Perpustakaan Perguruan Tinggi Keagamaan Islam Negeri (PTKIN) adalah menyediakan kebutuhan informasi sivitas akademika kampus yaitu kampus tercinta Institut Agama Islam Negeri (IAIN) Salatiga. 
Perpustakaan IAIN Salatiga menyediakan kebutuhan sumber-sumber referensi untuk seluruh Fakultas dan Program Studi yaitu Fakultas Tardris Ilmu Keguruan (FTKI) yang terdiri dari program studi PAI, TBI, PBA, PGMI, PIAUD, TIPA, TM, BKPI; Fakultas Dakwah yang terdiri dari program studi KPI, PMI, MD, PI ; Fakultas Ushuluddin Adab dan Humaniora (FUAH) yang terdiri dari program studi SPI, BSA, IAT, IH, AFI ; Fakultas Syariah yang terdiri dari program studi HKI, HES, HTN ; Fakultas Ekonomi dan Bisnis Islam (FEBI) yang terdiri dari program studi PS, ES, MBS, AS; dan Pasca Sarjana yang terdiri dari program studi PAI, ES dan PGMI.

Dari jumlah program studi yang banyak diatas maka perpustakaan berusaha membuat berbagai kegiatan promosi. Kegiatan promosi ini bertujuan menyampaikan kepada pengguna tentang inovasi layanan perpustakaan dan koleksi yang dimiliki oleh perpustakaan baik koleksi buku manual maupun koleksi digital yang dimiliki dan dilanggan oleh perpusakaan. Sehingga mampu memuaskan para calon cendikiawan untuk mendapatkan sumber-sumber informasi sesuai kebutuhan referensi yang dibutuhkan.

Tulisan ini akan membahas tentang: 1. Hakekat promosi dalam sebuah perpustakaan, 2. Manfaat dan Tujuan Penggunaan media sosial dalam promosi perpustakaan, dan 3. Jenis promosi perpustakaan yang dilakukan di Perpustakaan IAIN Salatiga Tujuan membahas 3 hal tersebut diatas adalah untuk menjelaskan tentang urgensi pemanfaatan media sosial dan kegiatan promosi untuk meningkatkan layanan informasi di perpustakaan IAIN Salatiga.

\section{Promosi Perpustakaan}

Perpustakaan adalah organisasi yang berkembang /growing organism Ranganathan (dalam Lasa HS, 1998: 39). Lima hukum ilmu perpustakaan (five laws of library) yang menyebutkan bahwa library is a growing organism. Perpustakaan merupakan organ, lembaga, maupun pusat kegiatan yang selalu tumbuh dan berkembang, baik koleksi, ruang, sistem pelayanan, maupun pemakainya. 
Promosi adalah bagian dari layanan perpustakaan untuk mengkomunikasikan sumber-sumber belajar yang tersedia baik koleksi non-digital maupun koleksi digital seluruh anggota perpustakaan. Maka perkembangan layanan perpustakaan harus terus beradaptasi dan menyesuaikan dengan perkembangan teknologi informasi dan komunikasi.

Menurut Darmono "Promosi adalah mekanisme komunikatif persuasif pemasaran dengan memanfaatkan teknik-teknik hubungan masyarakat”. Perpustakaan harus mampu mengkomunikasikan berbagai layanan, kegiatan, koleksi, fasilitas dan sebagainya kepada para penggunanya. Dan Promosi adalah bagian dari kegiatan pemasaran perpustakaan (library marketing). Promosi perpustakaan bersifat mengajak para pengguna untuk lebih dekat dengan perpustakaan. Sehingga pengguna paham betul apa saja yang bisa didapat di perpustakaan, kewajiban apa yang harus dipenuhi, hak apa yang akan diperoleh, fasilitas yang didapat, informasi apa saja yang dapat diperoleh (user oriented). Berorientasi pada pengguna atau yang biasa disebut dengan user oriented merupakan salah satu "semboyan" perpustakaan yang berusaha untuk dicapai, oleh sebab itulah dalam penentuan promosi perpustakaan juga berorientasi pada pengguna.

Dalam konteks ini pengguna perpustakaan mengalami perubahan sosial dari masa ke masa. Perpustakaan dalam konteks yang lebih luas memiliki tugas yaitu Working professionally by separating personal needs and professional obligations, as well as giving optimum service and information, bekerja secara professional memberikan layanan secara optimal termasuk di dalamnya informasi yang dibutuhkan pemustaka. Promosi adalah bagian dari menginformasikan hal-hal apa yang bermanfaat bagi pemustaka yang dimiliki oleh perpustakaan.(Wiji, 2018, p. 5)

Karakteristik pengguna di masa masyarakat pra industri berbeda dengan karakteristik pengguna di masa pasca industri (masyarakat informasi). Perkembangan teknologi informasi dan komunikasi (TIK) lah yang memberikan dampak paling besar pada perubahan sosial masyarakat (Ritzer, 2010). Mau tidak mau perpustakaan harus menyesuaikan dengan perubahan tersebut. 
Adapun Tujuan promosi perpustakaan menurut Edsall dalam Mustafa (1996: 21) adalah :

1. Memberikan kesadaran kepada masyarakat tentang pelayanan perpustakaan.

2. Mendorong minat masyarakat untuk menggunakan perpustakaan

3. Mengembangkan pengertian masyarakat agar mendukung kegiatan perpustakaan.

Dan dalam mempromosikan perpustakaan ada beberapa metode atau cara yang digunakan disesuaikan dengan kebutuhan pengguna sehingga promosi perpustakaan dapat tepat sasaran dan tidak sia-sia. Menurut Assauri, Sofyan, (2007 : 268-269) terdapat 4 variabel dalam sebuah promosi yaitu :

1. Advertensi. Dalam promosi melibatkan sponshorship / non personal, media yang digunakan yaitu radio, televisi, majalah, surat kabar, billboard.

2. Personal Selling, promosi lisan dalam suatu percakapan lisan dengan seseorang atau lebih konsumen.

3. Promosi Penjualan (sales promotion) merupakan tangan panjang dari agen besar untuk memasarkan produknya kepada konsumen.

4. Publisitas (Publicity), promosi yang berifat komersial dan dipublikasikan untuk menarik konsumen.

Saat ini perpustakaan IAIN Salatiga tidak menggunakan radio sebagai media promosi melainkan menggunakan media sosial baik facebook, youtube dan website.

\section{Promosi Perpustakaan via Media Sosial}

Pengguna perpustakaan di zaman sekarang di sebut dengan Net Generation, yaitu generasi yang lahir dan tumbuh dalam perkembangan kecanggihan teknologi informasi dan internet. Menurut Tapscott (2009) karakteristik net generation antara lain: freedom, customization, scrunity, integrity, collaboration, entertaiment, speed, dan innovation. Pihak perpustakaan harus menyesuaikan desain promosi perpustakaan dengan 
karakteristik net generation sebagai pengguna perpustakaan di zaman sekarang.

Misalnya pada karakteristik freedom atau kebebasan, bahwa para net generation ini tidak menyukai aturan yang mengekangnya, mereka cenderung bebas melakukan sesuatu sesuai dengan apa yang mereka inginkan. Maka promosi perpustakaan harus dikemas semenarik mungkin sesuai zamannya dengan teknik persuasif dan tidak ada paksaan.

Maka media yang digunakan untuk promosi haruslah dengan media yang digandrungi anak millennial. Perpustakaan dapat memilih berbagai media sosiasl yang disuguhkan di dunia maya. King (2015) menjelaskan ada beberapa jenis media sosial yang dapat dimanfaatkan oleh perpustakaan, diantaranya: Facebook, Twitter, Youtube, LinkedIn, Tumblr, Pinterest, Instagram, Snapchat, Vine, Google Plus, dan Flickr.

Jenis-jenis media sosial dapat dijelaskan sebagai berikut :

1. Facebook. Facebook digunakan untuk menambah pertemanan, mengirim teks serta foto maupun video. Sampai saat ini facebook masih menjadi media sosial yang digandrungi oleh kaum millennial.

2. Twitter. Twitter adalah saluran media sosial yang dapat meningkatkan jumlah presentase komunitas tertentu.

3. Youtube. Sebagian besar orang memanfaatkan Youtube untuk membagikan hasil rekaman video melalui saluran media online. Melalui Youtube kita bisa dapat berbagi konten ke teman mengomentarinya dan menyarankan mereka untuk memberikan rating, memfavoritkan, memasukkan dalam bookmark, dan men-share-nya melalui jejaring sosial.

4. LinkedIn. LinkedIn dikenal sebagai jaringan bisnis yang fokus pada spesifikasi dan pemanfaatan alat/media.

5. Tumblr. Tumblr adalah media sosial unik tujuan popularitas, dengan menampilkan informasi berbasis animasi dan visual.

6. Pinterest. Pinterest adalah media sosial yang baik untuk menemukan konten informasi visual yang menarik.

7. Instagram. Instagram adalah media sosial yang dimanfaatkan untuk 
berbagi foto dan video berdurasi pendek. Setelah Facebook membeli Instagram, fasiliitas dan fitur layanannya diperbaiki guna meningkatkan jumlah pelanggan Instagram.

8. Snapchat. Snapchat memungkinkan pengguna untuk mengirim foto dan video, menambah teks dan gambar untuk foto atau video, serta mengatur waktu durasi untuk menampilkan konten.

9. Vine. Vine merupakan alat baru untuk twitter posting. Pengguna Vine relative masih sedikit, tidak sepopuler dengan media sosial yang lain. Konten visual mirip dengan konten di Instagram, durasi video yang dapat di-upload di Vine hanya berlangsung enam detik.

10. Google Plus. Google Plus (Google+ atau G+) adalah jaringan sosial yang dikembangkan oleh Google. Sebelum G+, Google telah mengembangkan jaringan sosial Google Buzz.

11. Flickr. Flickr merupakan media sosial untuk menyimpan dan berbagi foto secara online. Pengguna Flickr dapat berbagi foto dengan teman yang menjadi komunitas, terutama melalui website pribadi.

12. WhatsApp. Whats App adalah media sosial terkini yang sama polulernya dengan facebook. Aplikasi ini sangat digandrugi kaum millennial, aplikasi ini bisa mengirimkan teks, video, foto, file pdf, Ms.Word, ppt dll

\section{Tujuan Penggunaan Media Sosial oleh Perpustakaan}

Hasil survey Taylor dan Francis di UK, US dan India, menyebutkan bahwa tujuan perpustakaan menggunakan media sosial adalah seperti terlihat pada Bagan1. 


\section{Bagan 1. Tujuan Penggunaan Media Sosial di Perpustakaan di UK, US dan India}

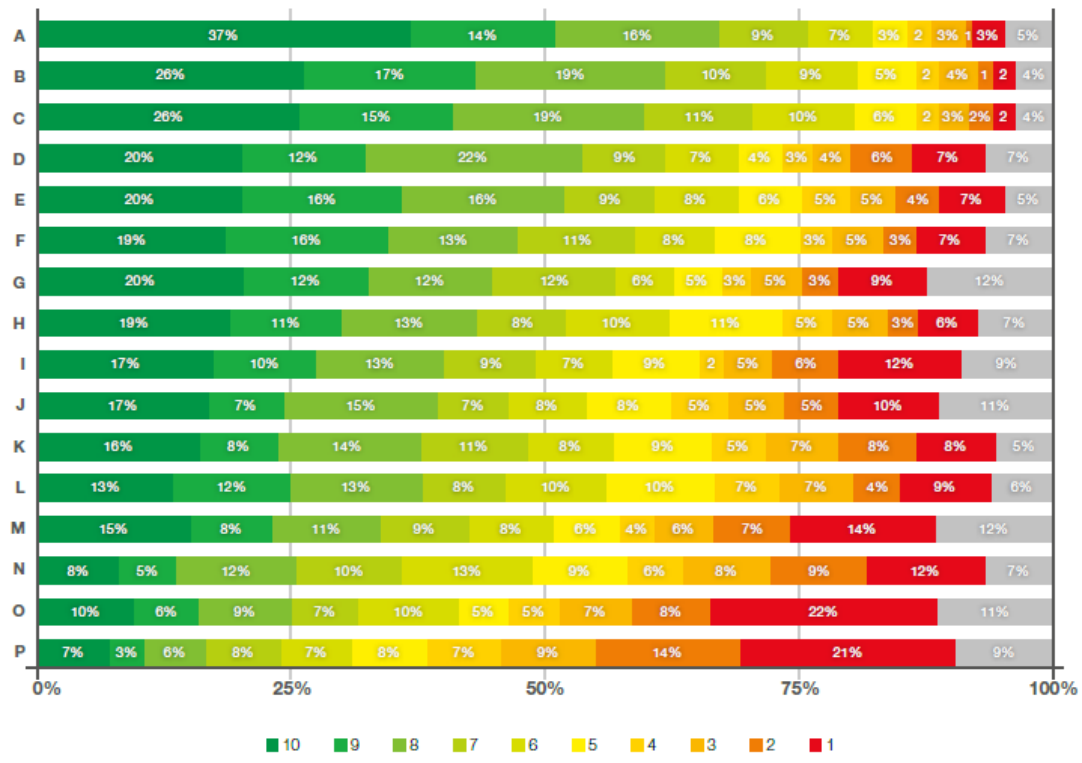

Sangat penting N/A Tidak terlalu penting Sumber : (Taylor and Francis 2014)

Keterangan dari bagan tersebut adalah sebagai berikut :

A untuk mempromosikan kegiatan.

B untuk mempromosikan layanan perpustakaan

C untuk mempromosikan sumber informasi/koleksi yang ada di perpustakaan

D untuk meng-update renovasi perpustakaan

E untuk mempromosikan pengadaan baru

F untuk mempromosikan panduan perpustakaan, panduan pameran

$\mathrm{G}$ untuk menghubungkan dengan mahasiswa baru dengan universitas

$\mathrm{H}$ untuk bergabung dengan komunitas akademik

I untuk terhubung dengan komunitas yang lebih luas 
J untuk terhubung dengan pembelajar jarak jauh

$\mathrm{K}$ sebagai alat layanan pelanggan yang dapat menampung complain, saran, permintaan dan umpan balik.

L untuk menandai informasi dengan subjek khusus.

$\mathrm{M}$ untuk terhubung dengan pelajar potensial

$\mathrm{N}$ sebagai alat pembelajaran yang mendukung literasi informasi, teknologi dan tips menulis (bukan berbasis berpustakaan)

$\mathrm{O}$ untuk mendukung mata pelajaran.

P sebagai alat penelitian untuk mencari dokumen dan studi resmi

Dari bagan tersebut dapat terlihat bahwa promosi masih menjadi tujuan utama penggunaan media sosial di perpustakaan.

\section{Manfaat Penggunaan Media Sosial oleh Perpustakaan}

Sedangkan menurut Kurniasih (2016) Manfaat penggunaan media sosial oleh perpustakaan antara lain :

1. Dapat meraih target audien yang lebih luas dengan biaya yang murah.

2. Meningkatkan interaksi dengan masyarakat.

3. Dapat meningkatkan pengguna perpustakaan melalui kegiatan promosi di media sosial.

4. Dapat meningkatkan kolaborasi dengan berbagai pihak sehingga layanan perpustakaan dapat lebih kuat.

5. Meningkatkan partisipasi masyarakat dalam membangun perpustakaan yang lebih baik.

6. Menghemat waktu dan biaya penyebaran informasi.

7. Memberikan akses layanan perpustakaan yang lebih luas dan cepat.

8. Mendapatkan umpan balik secara langsung lebih cepat.

9. Membantu dalam meningkatkan citra perpustakaan/ menjaga reputasi perpustakaan. 


\section{Promosi Perpustakaan di IAIN Salatiga}

Perpustakaan IAIN Salatiga selalu membuat inovasi promosi layanan dan kegiatan perpustakaan dengan memanfaatkan kecerdasan media sosial. Beberapa kegiatan promosi perpustakaan IAIN Salatiga adalah sebagai berikut :

1. Seminar Nasional/Workshop/Pelatihan berkolaborasi dengan organisasi profesi seperti IPI (Ikatan Pustakawan Indonesia) Kota Salatiga, FTBM (Forum Taman Bacaan Masyarakat Kota Salatiga), Dinas terkait seperti Dinas Perpustakaan dan Kearsipan Kota Salatiga, Dinas Pendidikan Kota Salatiga, FPPTI (Forum Perpustakaan Perguruant Tinggi) Jawa Tengah, FKP2TN (Forum Komunikasi Perpustakaan Perguruan Tinggi Negeri) Jawa Tengah dsb. Kegitan ini di sebar luaskan dengan menggunakan e-brosur yang disebar luaskan dengan media social baik WhatsApp Group, Facebook dan memalui website perpustakaan IAIN Salatiga.

2. Promosi Kegiatan melalui Website. Website perpustakaan IAIN Salatiga (http://perpus.iain.salatiga.ac.id) yang berisi dokumentasi kegiatan perpustakaan, link Youtube, link koleksi e-resources, sejarah perpustakaan, area anggota yaitu layanan pendaftaran anggota secara online, upload karya ilmiah secara online, area tamu, lokasi perpustakaan kampus 1, kampus 2, dan kampus 3, pengumuman dan berita.

3. Bimbingan Pemakai (User Education) yaitu pengenalan perpustakaan secara umum kepada mahasiswa baru dan pendaftaran anggota baru secara online.

Media yang digunakan untuk user education adalah video profile perpustakaan melalui media sosial Youtube dan Video Profile.

4. Bimbingan penelusuran informasi dalam kegiatan sosialisasi e-resources

- E-Repository: http://e-repository.iainsalatiga.ac.id yang berisi hasil karya ilmiah civitas akademika kampus IAIN Salatiga yang berupa tugas akhir, skripsi, tesis, disertasi, penelitian, artikel journal, buku, dan prosiding.

- OJS IAIN Salatiga : https://e-journal.iainsalatiga.ac.id/ yang berisi 
seluruh jurnal yang ada di IAIN Salatiga yaitu :

- Indonesian Journal of Islam and Muslim Societies

- INFERENSI: Jurnal Penelitian Sosial Keagamaan

- Ijtihad : Jurnal Wacana Hukum Islam dan Kemanusiaan

- Register Journal

- MUDARRISA: Jurnal Kajian Pendidikan Islam

- ATTARBIYAH: Journal of Islamic Culture and Education

- Muqtasid: Jurnal Ekonomi dan Perbankan Syariah

- INJECT (Interdisciplinary Journal of Communication)

- LISANIA: Journal of Arabic Education and Literature

- Millati: Journal of Islamic Studies and Humanities

- Journal Practice

- Journal of Pragmatics Research

- Hipotenusa : Journal of Mathematical Society

- Pustabiblia: Journal of Library and Information Science

- Indonesian Journal of Islamic Economics Research

- IJIP : Indonesian Journal of Islamic Psychology

- Islamic Management and Empowerment Journal

- Journal of Madrasa Studies

- Open Conference System

- Moraref : https://moraref.kemenag.go.id/ yang berisi seluruh jurnal yang ada di Perguruan Tinggi Keagamaan di Direktorat Jenderal Pendidikan Islam Kementerian Agama Republik Indonesia. Seperti Jurnal dari seluruh STAIN, IAIN, UIN se-Indonesia dsb.

- Morabase http://morabase.kemenag.go.id/ yaitu sistem yang dibuat Direktorat Jenderal Pendidikan Islam Kementerian Agama Republik Indonesia untuk menangkap banyak hasil penelitian yang belum terpublikasikan, dan menjembatani penulis untuk mencarikan jurnal berkualitas.

- Pustabiblia adalah layanan aplikasi ebook yang dimiliki oleh 
perpustakaan IAIN Salatiga yang merupakan sumbangan para alumni. Aplikasi ebook ini dapat di-install di Handphone (HP) android dan dapat di-install melalui Personal Computer (PC).

- IPI Portal Garuda (http://id.portalgaruda.org) The Indonesian Publication Index (IPI) merupakan situs akademik yang didesain untuk mencari, mengindeks, memonitor dan mengembangkan standar publikasi ilmiah di Indonesia. (pencarian artikel jurnal)

- Indonesia One Search (http://onesearch.id) Indonesia OneSearch adalah situs portal repositori perpustakaan di seluruh Indonesia yang dikembangkan oleh Perpustakaan Nasional RI

- E-Resources Perpusnas RI (http://e-resources.perpusnas.go.id) yang berisi ebook, ejournal, e-artikel, video yang dilanggan oleh Perpusnas RI melalui beberapa portal akademik sebagai berikut : Gambar 3. E-Resources Perpusnas RI

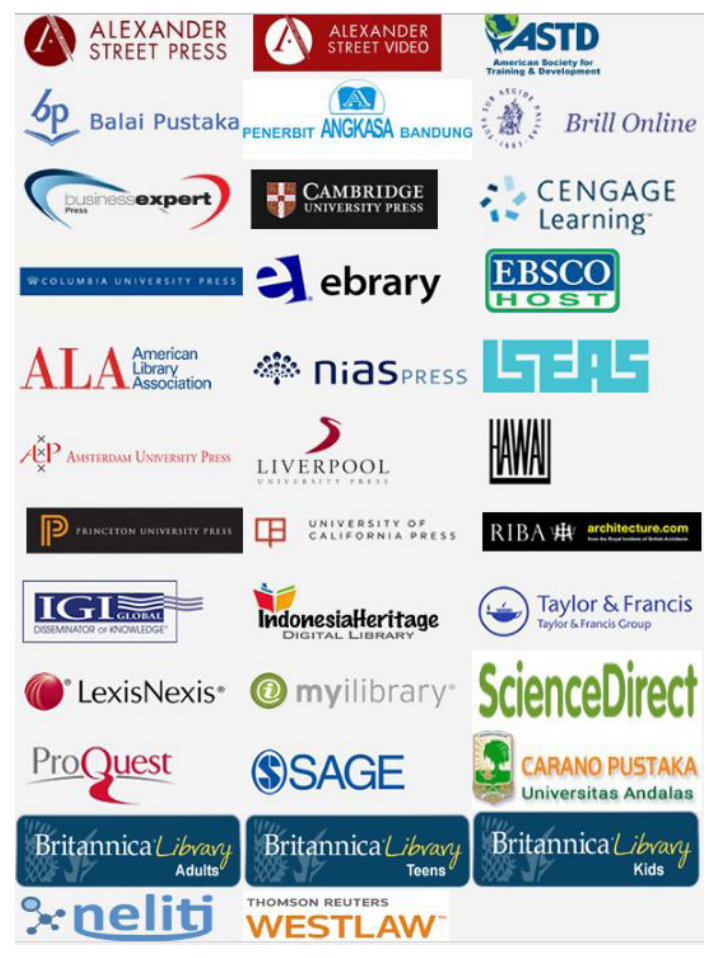


Dan beberapa link open access yang dapat digunakan oleh civitas akademika kampus IAIN Salatiga sebagai berikut :

- BSE Kemendikbut RI (http://bse.kemendikbud.go.id)

- SpringerLink (http://link.springer.com)

- JSTOR (http://www.jstor.org/?redirected=true)

- DOAJ (https://doaj.org)

- DOAB (http://www.doabooks.org/)

- OATB (https://oatd.org/)

- OAPEN (http://www.oapen.org/)

- OpenDOAR (http://www.opendoar.org)

- Open Book (http://bookzz.org) dan http://en.bookfi.net/)

- OpenDocs (http://opendocs.ids.ac.uk/opendocs)

- OpenPatent (http://www.uspto.gov/; https://worldwide.espacenet. com/; http://www.freepatentonline.com)

- The Nasional Acedemies Press (https://www.nap.edu/)

- Scopus (http://www.scopus.com/)

- ScimagoJR (http://www.scimagojr.com/journalrank.php)

Kegiatan promosi tersebut dilakukan secara individu melalui pustakawan/ petugas perpustakaan maupun melalui media video yang diupload di akun Youtube perpustakaan IAIN Salatiga saat ini sedang dikembangkan.

5. Literasi Kitab. Mengenalkan penggunaan kitab-kitab berbahasa arab sehingga dapat digunakan oleh seluruh mahasiswa dan kalayak umum yang diadakan secara rutin baik individu maupun klasikal. Saat akan dikembangkan untuk diunggah dan diabadikan di akun Youtube perpustakaan IAIN Salatiga. https://www.youtube.com/ watch? $=\mathrm{QBc} 3 \mathrm{RFvQBIY}$

6. Bedah Buku. Membedah buku karya dosen-dosen di IAIN Salatiga untuk meningkatkan karya local content civitas akademika kampus. Saat ini akan dikembangkan dan diabadikan di akun Youtube perpustakaan IAIN Salatiga. Contoh link Youtube bedah buku di perpustakaan IAIN 
Salatiga yaitu : https://www.youtube.com/watch?v=oLRwvqmFhrM

7. Kolaborasi Kegiatan bersama organisasi Profesi diantaranya IPI Kota Salatiga, FTBM Kota Salatiga, FPPTI Jateng, APPTIS Jawa Tengah, APPTIS Jawa Timur dan sekolah di sekitar Kota Salatiga. Komunikasi yang digunakan adalah aplikasi WhatsApp Group untuk berdiskusi perkembangan perpustakaan di masing-masing perguruan tinggi dan media sosial yang digunakan yaitu Youtube. Contoh berapa kegiatan kolaborasi https://www.youtube.com/watch?v=jQYHss9UUk8

\section{Penutup}

Kesimpulan dari penulisan ini adalah bahwa Promosi sebagai salah satu kegiatan library marketing (pemasaran perpustakaan) menjadi kunci dari keberlangsungan keterpakaian perpustakaan oleh para penggunanya. Begitu juga keberadaan media sosial bukan menjadi pesaing melainkan menjadi sarana untuk promosi yang memudahkan para pustakawan untuk berkomunikasi dengan para pengguna. Perpustakaan IAIN Salatiga menggunakan media sosial berupa website dan akun Youtube sebagai media promosi untuk mengkomunikasi layanan-layanan, kegiatan-kegiatan, dan kekayaan sumber referensi yang dimilikinya kepada para pengguna.

\section{Daftar Pustaka}

Assauri, Sofyan. 2007. Manajemen Pemasaran, Raja Grafindo Persada, Jakarta.

Barner, K. (2011). The library is a growing organsim: Ranganathan's fifth law of library science and the academic library in the digital era. Library Philosophy and practice, 548.

Darmono. 2007. Perpustakaan Sekolah: Pendekatan Aspek Manajemen dan Tata Kerja. Jakarta: Grasindo.

Gambar. 2 dan Tabel . 1 http://www.lppslh.or.id/artikel/analisis-swot/ 
Handayani, Juli. 2017. Kegiatan Promosi Pada Perpustakaan : Makalah Pustakawan Universitas Sumatera Utara. http://repositori.usu.ac.id/ handle/123456789/6427

Horrison, Jeffrey P. 2010. Essential of Strategic Planning in Healthcare. Chicago: Health Administration Press.

King, David Lee. 2015. Managing Your Library's Sosial Media Channels. Volume 51, Number 1. USA: America Library Association.

Kurniasih, Nuning. 2016. Optimalisasi Penggunaan Media Sosial untuk Perpustakaan : Prosiding Makalah Seminar Nasional "Komunikasi, Informasi dan Perpustakaan di Era Global” Fikom Unpad, Jatinangor.

Lasa Hs. 1998. Kamus Istilah Perpustakaan. Yogyakarta : Gadjah Mada University Press.

Mustafa, Badollahi. 1996. Promosi Jasa Perpustakaan. Jakarta: Universitas Terbuka.

Nashihuddin, Wahid. 2016. Makalah Presentasi Rapat Kerja Pusat XX dan Seminar Ilmiah Nasional Ikatan Pustakawan Indonesia. Bandung.

Sulistyo-Basuki. 1994. Periodisasi Perpustakaan Indonesia. Bandung: PT. Remaja Rosdakarya.

Tapcott, D. (2009). Grown up digital: How the net generation is changing your world. New York: Mc Graw Hill.

Taylor \& Francis Group. 2014. Use of Social Media by the library current practices and future opportunities: A White Paper From Taylor \& Francis.

Undang-undang Republik Indonesia Nomor 43 Tahun 2007 tentang Perpustakaan. Jakarta: Perpustakaan Nasional Republik Indonesia.

Wiji, S. (2018). Attitudes and roles of librarians in the modern era (an ethical and cultural approach). International Journal of Library and Information Science, 10(4), 41-44. https://doi.org/10.5897/ IJLIS2016.0667 